\title{
PENINGKATAN KUALITAS VISUAL LANSKAPJALAN DI SEMPADAN SETU BABAKAN PADA AREA WISATA SETU BABAKAN
}

\author{
Daisy Radnawati ${ }^{*}$, Laraswati, Sitti Wardiningsih \\ Program Studi Arsitektur Lanskap, Fakultas Teknik Sipil dan Perencanaan, \\ Institut Sains dan Teknologi Nasional, Jl.Moh Kahfi Il Srengseng Sawah Jagakarsa \\ Jakarta Selatan, 12640 \\ daisy.arl@istn.ac.id
}

\begin{abstract}
ABSTRAK. Perkampungan Budaya Betawi (PBB) merupakan satu kawasan dengan komunitas yang ditumbuhkembangkan dengan Budaya Betawi meliputi hasil gagasan dan karya baik fisik maupun nonfisik yaitu kesenian, adat istiadat, foklor, kesasteraan, bahasa, tanaman dan bangunan yang bercirikan keBetawian. Batasan area penelitian ini adalah Perencanaan Lanskap jalan di sempadan Setu Babakan dan pulau jalan yang ada sebagai pusat wisata dalam kawasan PBB Setu Babakan. Secara visual Setu Babakan bisa dikatakan sejuk dan asri, terlihat dari adanya pohon-pohon existing yang mengelilingi bantaran Setu Babakan yang memberikan fungsi ekologis pada suatu kawasan. Pohon tersebut juga menghasilkan bayangan pada air Setu, sehingga seperti bercermin dan memberikan estetika visual yang baik. Namun beberapa area komersial dan parkir yang yang berada di sebelah barat dan timur memberikan dampak yang kurang baik. Metode pada penelitian ini menggunakan pendekatan J. Simonds (1983). Penelitian ini bertujuan untuk membuat perencanaan lanskap jalan di sempadan Setu Babakan yang dapat memberikan identitas kawasan Setu Babakan sebagai area wisata, dan dapat memberikan nilai tambah bagi kawasan tersebut. Selain itu dapat meningkatkan kualitas visual pada kawasan Setu Babakan serta memberikan pelayanan bagi seluruh pengguna jalan yang nyaman, aman dan memperhatikan kelestarian lingkungan di sekitarnya.
\end{abstract}

Kata kunci: Perencanaan Lanskap, Ornamen Betawi, Wisata Setu Babakan

ABSTRACT. The Betawi Cultural Village (PBB) is an area with a community that is cultivated with Betawi Culture which includes the results of ideas and works both physical and non-physical, namely art, customs, folklore, literature, language, plants, and buildings characterized by Brethren. The boundary of this research area is the Landscape Planning road in the border of Setu Babakan and the island of the street that exists as a tourist center in the Perkampungan Budaya Betawi Setu Babakan region. Visually, Setu Babakan can be said to be relaxed and beautiful, as seen from the existing trees surrounding the banks of Setu Babakan which provide ecological functions in an area. The tree also produces shadows on Setu water, so it looks like a mirror and offers good visual aesthetics. However, some commercial and parking spaces which are in the west and east have an adverse impact. The method J. Simonds (1983) approach includes design planning in the stages of preliminary activity, inventory, analysis, synthesis, construction, concepts, and designs. This study aims to make a road landscape planning in the Setu Babakan border that can provide the identity of the Setu Babakan area as a tourist area, and can provide added value to the district. Besides, it can improve the visual quality of the Setu Babakan area ludes design planning in the area and offer services to all road users who are comfortable, safe and pay attention to the preservation of the surrounding environment.

Keywords: Landscape Planning, Betawi Ornaments, Setu Babakan Tourism

\section{PENDAHULUAN}

Perkampungan Budaya Betawi (PBB) terletak di Jalan Mochamad Kahfi II. Setu Babakan Kelurahan Serengseng Sawah, Kecamatan Jagakarsa, Jakarta Selatan. Perkampungan Budaya Betawi (PBB) merupakan satu kawasan dengan komunitas yang ditumbuhkembangkan dengan Budaya Betawi meliputi hasil gagasan dan karya baik fisik maupun nonfisik yaitu kesenian, adat istiadat, foklor, kesasteraan, bahasa, tanaman dan bangunan yang bercirikan keBetawian. Selain itu PBB juga dilengkapi dengan dua buah setu alam yakni Setu Babakan, dan Setu Mangga Bolong yang memiliki potensi lingkungan alam dengan panorama yang asri dan indah, dimana disepanjang pinggiran setu tersebut ditanami tanaman yang bercirikan Betawi seperti kecapi, rambutan rapiah, sawo, melinjo, boni, secang, namnam, jamblang, jeruk purut, dan lain-lain.

PBB yang memiliki luas seluruhnya \pm 289 ha terletak di empat Rukun Warga (RW). yaitu RW 06, RW 07, RW 08, dan RW 09 Kelurahan Serengseng Sawah, Kecamatan Jagakarsa, Jakarta Selatan. Sebagai Pusat kegiatan Perkampungan Budaya Betawi berada di RW. 
08, dimana disana terdapat pusat kegiatan wisata budaya betawi, kantor pengelola Perkampungan Budaya Betawi, museum/galeri mini, wisma, rumah adat, dan tempat penjualan souvenir.

Lokasi Perkampungan Budaya Betawi yang berada dipinggiran kota Jakarta, jauh dari kesibukan dan kebisingan kota, serta dengan adanya perpaduan wisata Budaya, wisata agro, dan wisata air menjadikan Kawasan Wisata PBB sebagai objek wisata yang unik dan sangat menarik untuk dikunjungi. Walaupun PBB terletak di pinggiran kota Jakarta, jarak PBB tidak jauh dari pusat kota Jakarta yaitu sekitar $\pm 42,5 \mathrm{~km}$ dari Bandara Internasional Seokarno-Hatta sehingga PBB dapat ditempuh \pm 45-60menit dengan menggunakan kendaraan, dan sekitar $\pm 30-45$ menit jika ditempuh dari hotel-hotel berbintang di Jakarta.

Upaya mengembangkan jalur hijau di sempadan Setu Babakan menjadi salah satu fasilitas yang merupakan bagian dari wisata yang harus dilakukan dengan pengelolaan dan perencanaan yang sistematis agar kawasan jalur hijau Setu Babakan berkembang menjadi daerah resapan yang baik, juga menjadi identitas kawasan Setu Babakan sebagai tempat wisata andalan di Selatan Jakarta.

Sebagian besar jalan yang melingkari Setu Babakan setiap hari dipadati oleh kendaraan bermotor dari pagi sampai sore hari terutama pada hari libur, dimana kondisi tersebut berdampak langsung pada pejalan kaki maupun badan jalan disekitarnya. Penggunaan lahan di Setu Babakan yang lebih didominasi sebagai area komersil dan resting area pada jalur hijau maupun jalur pejalan kaki, sehingga diperlukan berupa fasilitas-fasilitas jalan yang bermanfaat, memadai, dan memberikan kenyamanan bagi pengguna jalan di kawasan Setu Babakan. Sehingga diharapkan dalam pengembangannya diperlukan suatu perencanaan lanskap jalan yang baik, lanskap jalan yang mendukung aktivitas industri pariwisata serta menjadi ciri khas lanskap jalan bagi pariwisata di Jakarta Selatan. Batasan area penelitian adalah Perencanaan Lanskap jalan di sempadan Setu Babakan dan pulau jalan yang ada sebagai pusat wisata dalam kawasan PBB Setu Babakan.

Penelitian ini bertujuan untuk membuat perencanaan lanskap jalan di sempadan Setu Babakan yang dapat memberikan identitas kawasan Setu Babakan sebagai area wisata, dan dapat memberikan nilai tambah bagi kawasan tersebut. Selain itu dapat meningkatkan kualitas visual pada kawasan Setu Babakan serta memberikan pelayanan bagi seluruh pengguna jalan yang nyaman, aman dan memperhatikan kelestarian lingkungan di sekitarnya.

Menurut Simonds, lanskap jalan harus bermanfaat dan secara kualitas menyenangkan bagi pengguna jalan, jika memiliki keharmonisan dan kesatuan dengan topografi dan mampu memenuhi seluruh kebutuhan fungsi secara fisik dan visual. Konsep dasar lanskap jalan adalah memberikan keamanan, kenyamanan, identitas dan keselamatan bagi pengguna jalan dan dapat mengeliminasi pengaruh negatif dari aktivitas jalan terhadap masyarakat sekitarnya. Lansekap Jalan adalah wajah dari karakter lahan atau tapak yang terbentuk pada lingkungan jalan, baik yang terbentuk dari elemen lansekap alamiah seperti bentuk topografi lahan yang mempunyai panorama yang indah, maupun yang terbentuk dari elemen lansekap buatan manusia yang disesuaikan dengan kondisi lahannya [1].

Lanskap jalan memiliki ciri yang khas karena harus disesuaikan dengan persyaratan geometrik jalan dan diperuntukkan terutama bagi kenyamanan pemakai jalan serta diupayakan dapat menciptakan lingkungan jalan yang indah, nyaman dan memenuhi fungsi keamanan (Departemen Pekerjaan Umum, 1996). Dengan adanya jalur hijau maka dapat mengurangi kemonotonan kekakuan aspal dan beton [2]. Selain itu, dengan penempatan pohon di sepanjang jalan menurut Carpenter et al [3] dapat memberikan suatu naungan, memberikan kesan, mengarahkan pada suatu objek, menyediakan aset visual dan menciptakan sense of unity and stability. Jalur hijau ditujukan untuk memisahkan pejalan kaki dari jalur kendaraan bagi keselamatan pejalan kaki [4]. Selain itu dimanfaatkan pula untuk memberikan informasi jalur jalan, memberi ruang bagi utulitas, memberi ruang untuk pemasangan perlengkapan jalan dan vegetasi jalan.

Prinsip yang biasa digunakan dalam merencanakan suatu lanskap adalah dengan mengeliminasi elemen-elemen yang buruk dan menonjolkan elemen elemen yang baik. Dalam lanskap, karakter tapak yang menarik harus diciptakan atau dipertahankan sehingga semua elemen yang banyak variasinya ini menjadi kesatuan yang harmonis [1]. Nurisyah menyatakan bahwa perencanaan lanskap adalah salah satu bentuk utama kegiatan arsitektur lanskap [5]. 
Simonds menyatakan bahwa perencanaan lanskap jalan yang baik adalah bervariasi dalam bentuk, ukuran, tekstur, warna, serta mempertimbangkan panorama (view) di sekitarnya melalui pembingkaian pemandangan yang baik dan penutupan pemandangan yang buruk. Pemandangan yang bebas ke arah gunung, persawahan, padang rumput atau bentukan lain yang menyenangkan manusia yang melihatnya merupakan salah satu potensi yang dapat direkayasa sedemikian rupa sehingga mudah dilihat.

Karakteristik pedestrian dapat diumpamakan sebagai aliran sungai dimana dalam pergerakannya akan mencari hambatan yang terkecil. Jalur yang diambil adalah jalur-jalur terpendek dari satu titik ke titik lainnya, sehingga jalur sirkulasinya memotong rintangan di depannya. Aspek fungsional dan estetik merupakan dua hal yang harus menjadi pertimbangan dalam sirkulasi pedestrian, dimana keduanya harus dapat dipadukan secara bersama-sama untuk mendapatkan sebuah sistem pedestrian yang baik.

Aspek fungsional yang menjadi pertimbangan antara lain kenyamanan, keamanan dan kepuasan yang diberikan kepada pejalan kaki. Sedangkan aspek estetika yang menjadi pertimbangan dapat diciptakan melalui penyusunan ruang dan pemandangan sepanjang tapak, sehingga tercapai sebuah jalur pedestrian dengan kualitas visual yang menarik.

Harris dan Dines membedakan pedestrian menjadi 3 jenis yaitu [6] :

1. Pedestrianisasi penuh (full pedestrianitation). Dengan menghilangkan atau melarang semua kendaraan bermotor untuk sepanjang waktu, terkecuali untuk pemeliharaan tapak, full pedestrianitation biasanya menghilangkan badan jalan untuk kendaraan dan menjadikan jalan secara kontinu ditutupi oleh paving dengan tekstur permukaan yang konsisten. Pedestrian ini membutuhkan jalan terdekat sebagai akses terdekat jalur bus/ angkutan umum.

Dengan ditiadakannya kendaraan bermotor maka dibutuhkan sekali suatu desain yang sangat baik, untuk mencapai daerah pedestrian ini harus memberi kesan yang jelas bahwa kendaraan akan memberi gangguan terhadap lingkungan pejalan kaki. Contohnya adalah pedestrian street dan pedestrian mall yang biasanya terdapat di daerah komersial dan ditujukan untuk kenyamanan pejalan kaki.
2. Pedestrian sebagian (partial pedestrianitation). Pedestrian Dapat mengurangi jenis kendaraan bermotor, terutama kendaraan pribadi, daerah ini diprioritaskan untuk kepentingan pejalan kaki. Jalur pejalan kaki diperbesar dan jalur kendaraan bermotor diperkecil maksimum dua jalur. Kendaraan pribadi dilarang masuk terkecuali angkutan umum, taksi dam bus. Laju kendaraan dibatas kecepatan tertentu. (Gambar 1)

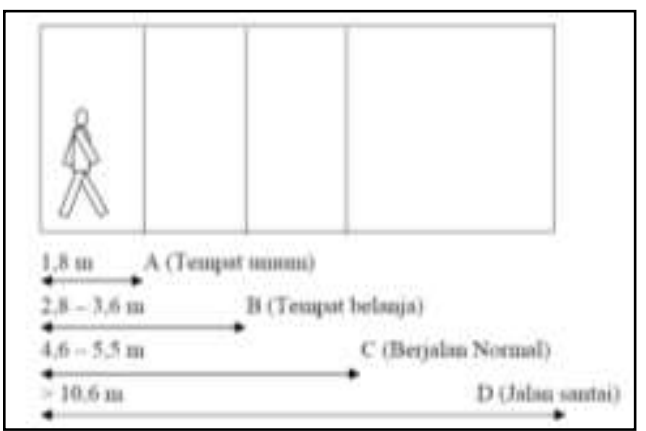

Gambar 1. Jarak ruang yang dibutuhkan antar pejalan kaki di depannya sesuai lokasi

(Sumber: Harris dan Dines, 1986)

3. Pedestrian Distrik. Dibuat dengan menghilangkan lalu lintas kendaraan dari sebagian daerah perkotaan dengan mempertimbangkan alasan adanya unit arsitektural, komersial maupun sejarah. Kota-kota di Eropa sering kali menggunakan jenis ini karena sesuai dengan kondisi daerah pusat kota yang bersejarah.

Harris dan Dines menyatakan bahwa street furniture atau perabot jalan adalah semua elemen yang ditempatkan secara kolektif pada suatu lanskap jalan untuk kenyamanan, kesenangan, informasi, kontrol sirkulasi, perlindungan dan kenikmatan pengguna jalan. Elemen ini harus merefleksikan karakter dari lingkungan setempat dan menyatu dengan keadaan sekitar. Menurut Departemen Pekerjaan Umum Direktorat Jenderal Bina Marga (1995), street furniture/ perabot jalan adalah fasilitas yang ditempatkan di sepanjang jalan yang merupakan pelengkap atau pendukung bagi jalur pejalan kaki. Penyediaannya disesuaikan dengan jenis kawasan yang mengunakan jalur pejalan kaki [6].

Kriteria elemen yang digunakan meliputi bahan yang mudah di dapat, kuat terhadap cuaca, mudah dalam perawatan, mudah dalam perbaikan, kuat dan aman bagi pengguna jalan maupun lingkungan sekitarnya [6]. Sarana pelengkap jalan ini sangat dibutuhkan untuk memenuhi fungsi sebagai berikut : 
- Fungsi keamanan dan kenyamanan adalah lampu, halte, jalan penyeberangan, ramburambu lalu-lintas, unsur tanaman sebagai peneduh, fire hydrant, pos pengaman dan jalur pejalan kaki.

- Fungsi pelengkap adalah tempat duduk, tempat sampah, telepon. kotak surat, wadah tanaman, papan informasi dan lain-lain.

- Fungsi estetik dapat diperoleh dari jenis elemen yang digunakan baik soft material maupun hard material di lihat dari bentuk, tekstur maupun warnanya.

\section{METODE PENELITIAN}

Penelitian dilakukan pada area jalan lingkar Setu Babakan, Srengseng Sawah, Jagakarsa, Jakarta Selatan. Penelitian dilakukan selama enam bulan,dari bulan Maret 2015 sampai bulan Agustus 2015. (Gambar 2. Lokasi penelitian ).

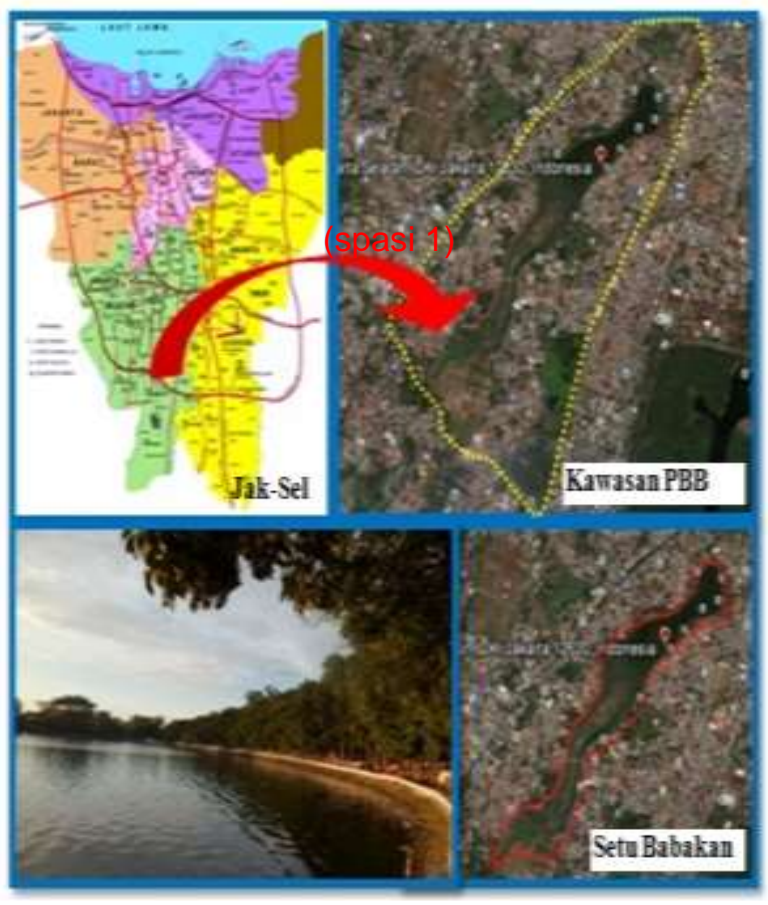

Gambar 2 Lokasi Penelitian

(Sumber: Hasil Observasi dan google earth, 2015)

Metode penelitian ini menggunakan metode kualitatif dan kuantitatif dengan teknik observasi atau survei tapak, studi pustaka, wawancara untuk memperoleh data berupa data primer dan sekunder. Data primer di dapat dari hasil survei, pengamatan langsung, dan wawancara. Sedangkan data sekunder diperoleh dari studi pustaka.

Metode perencanaan yang digunakan adalah pendekatan sistematis untuk perencanaan tapak yang dikemukakan oleh J Simonds [1].
Metode kuesioner menurut Arikunto digunakan digunakan untuk memperoleh informasi dari responden dalam arti laporan tentang pribadi atau hal-hal yang ia ketahui [7].

Metode kuesioner adalah daftar pertanyaan yang disiapkan oleh peneliti dimana tiap pertanyaanya berkaitan dengan penelitian. Kuesioner tersebut pada akhirnya diberikan kepada responden untuk dimintakan jawaban. Metode sampel digunakan untuk mengetahui berapa jumlah kuesioner yang harus disebar.

Metode sampel yang digunakan adalah random sampling, karena metode ini relatif murah dan mudah untuk dilaksanakan. Besarnya jumlah populasi dan keterbatasan yang ada, pengumpulan data primer melalui penyebaran kuesioner dilakukan hanya satu jenis responden yaitu penghuni, pengunjung maupun pengelola. Dalam penelitian ini teknik pengambilan sampel dengan menggunakan metode random sampling menurut Sugiarto [8] dengan rumus :

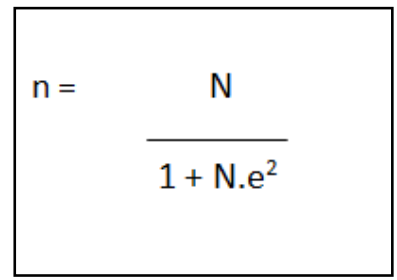

Dimana :

$\mathrm{N} \quad$ : Ukuran populasi

$\mathrm{N} \quad$ : Ukuran sampel

e : Persen kelonggaran ketidaktelitian karena kesalahan pengambilan sampel yang tidak dapat ditolerir

Sampel disebarkan kepada responden yaitu untuk penduduk yang berada di perkampungan Budaya Betawi, Berdasarkan data yang diperoleh jumlah pengunjung PBB terdapat 600 jiwa. Maka dengan menggunakan metode sampel dapat diketahui :

$$
\begin{aligned}
& \mathrm{N}=15.384 \\
& \mathrm{e}=600 \\
& \mathrm{n}=\mathrm{N}\left(1+\mathrm{N} \cdot \mathrm{e}^{2}\right) \\
& \mathrm{n}=\underline{600} \\
& \left.(1+600,15)^{2}\right) \\
& \mathrm{n}=\underline{600} \\
& \quad \underline{601.0,02}
\end{aligned}
$$$$
\mathrm{n}=49
$$

\section{HASIL DAN PEMBAHASAN}

Kondisi Eksisting di Sekitar Tapak disekitar area jalan lingkar Setu Babakan, terdapat lingkungan sekitar yang terdiri dari area jalan, pedestrian, permukiman, area rekresai, kuliner, pemancingan, dan fasilitas pendukungnya. 
Berdasarkan Laporan Status Lingkungan Hidup Daerah Provinsi DKI Jakarta (2011) kondisi setu tergolong baik, meskipun tidak jarang ditemukan banyak sampah di sekitar setu [9]. Setu Babakan masih tergolong alami, jernih, bersih. Inlet air Setu berasal dari Setu Mangga Bolong, Danau Institut Sains dan Teknologi Nasional (ISTN), dan Kali Baru. Sedangkan Outlet menuju sungai Ciliwung. Terdapat juga pintu air yang terdapat di Setu Babakan pada outlet pengeluaran air. Gambar 3.

Berdasarkan hasil pengamatan dilapangan didapatkan data sebagai berikut:

- Panjang jalan $4 \mathrm{~km}$

- Badan jalan Mengelilingi area tapak, lebar $6 \mathrm{~m}$

- Jalur pejalan kaki Mengelilingi area tapak utara :-

Selatan : $1,75 \mathrm{~m}$

Barat : $1,20 \mathrm{~m}$

Timur : $1,20 \mathrm{~m}$

- Lampu dengan tinggi $6 \mathrm{~m}$

- Gardu utama 1 unit berada di sebelah selatan,

- panel listrik pendukung mengelilingi tapak

- Pot tanaman terdapat pada bagian barat, tinggi $1 \mathrm{~m}$.

- Bolard terdapat di sebelah barat (tinggi : $40 \mathrm{~cm}$ lebar $60 \mathrm{~cm}$ )

- Tempat sampah lebih didominasi di wilayah barat.(tinggi $60 \mathrm{~cm}$ ). Gambar 3

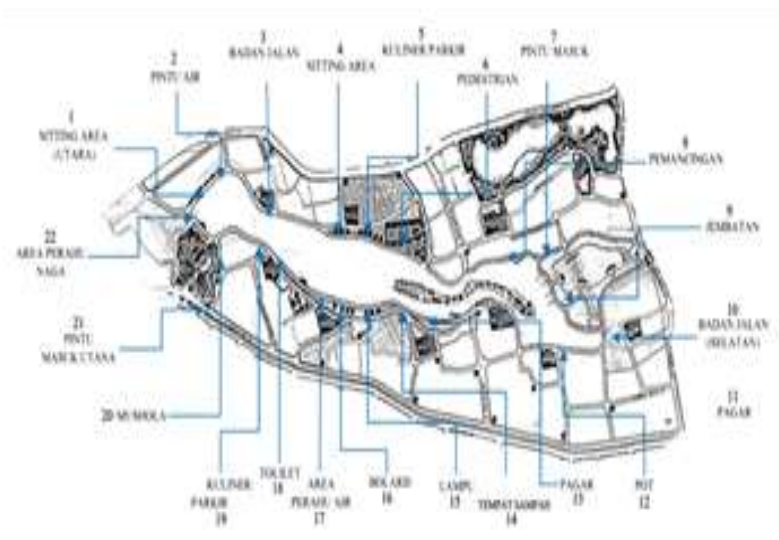

Gambar 3 Kondisi Eksisting Tapak (Sumber: Kawasan Setu 2012)

Kondisi Visual di area jalan lingkar Setu Babakan secara visual Setu Babakan bisa dikatakan sejuk dan asri, terlihat dari adanya pohon-pohon existing yang mengelilingi bantaran Setu Babakan yang memberikan fungsi ekologis pada suatu kawasan. Pohon tersebut juga menghasilkan bayangan pada air Setu, sehingga seperti bercermin dan memberikan estetika visual yang baik. Namun beberapa area komersial dan parkir yang yang berada di sebelah barat dan timur memberkan dampak yang kurang baik.Gambar 4 Pada bagian sebelah utara (bendungan) juga terdapat sampah yang berada di atas permukaan air setu. Gambar 4.

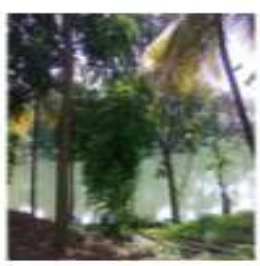

DanisT

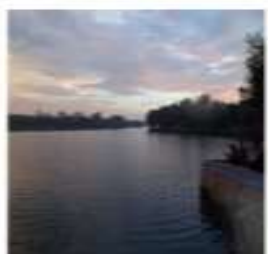

Sarablare

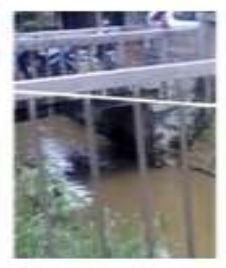

KaiBar
Gambar 4: Kondisi Inlet dan uot let ar danau (Sumber:: Hasil Observasi 2015)

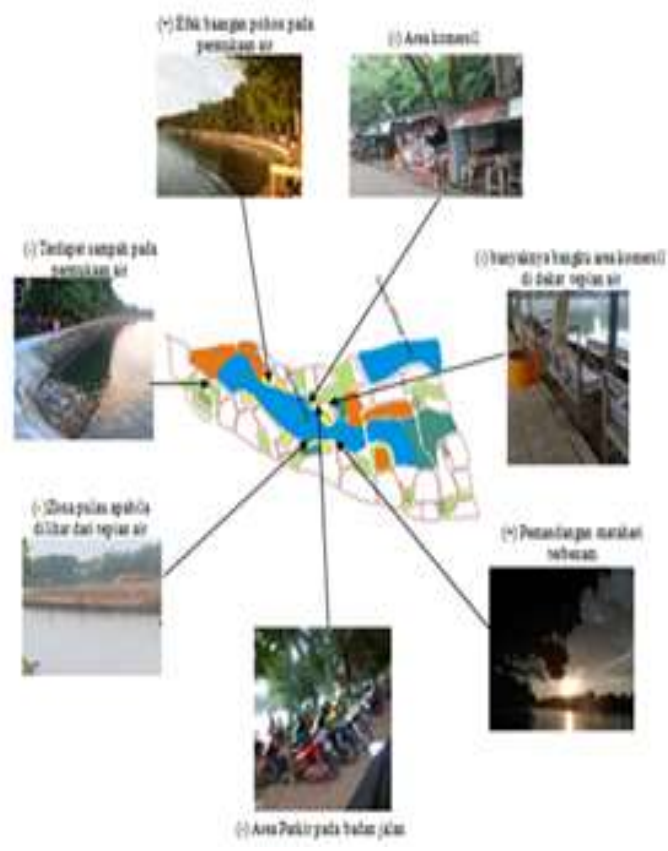

Gambar 5 .Kondisi Visual di Sekitar Tapak (Sumber: Hasil Observasi 2015)

Pada area jalan di kawasan Setu Babakan terdapat elemen-elemen hardscape / street furniture yang melengkapi area jalan di Setu Tanaman di lingkar jalan di Setu Babakan didominasi oleh tanaman-tanaman peneduh. Gloodogan bulat terdapat di titik bagian utara, Karet kebo pada bagian timur tapak.Pohon bintaro terdapat di beberapa titik pada bagian barat dan timur. Ketapang terdapat pada titik bagian timur, Kersen berada pada beberapa titik di bagian timur dan selatan tapak. Babakan, antara lain seperti pada Gambar 6. 


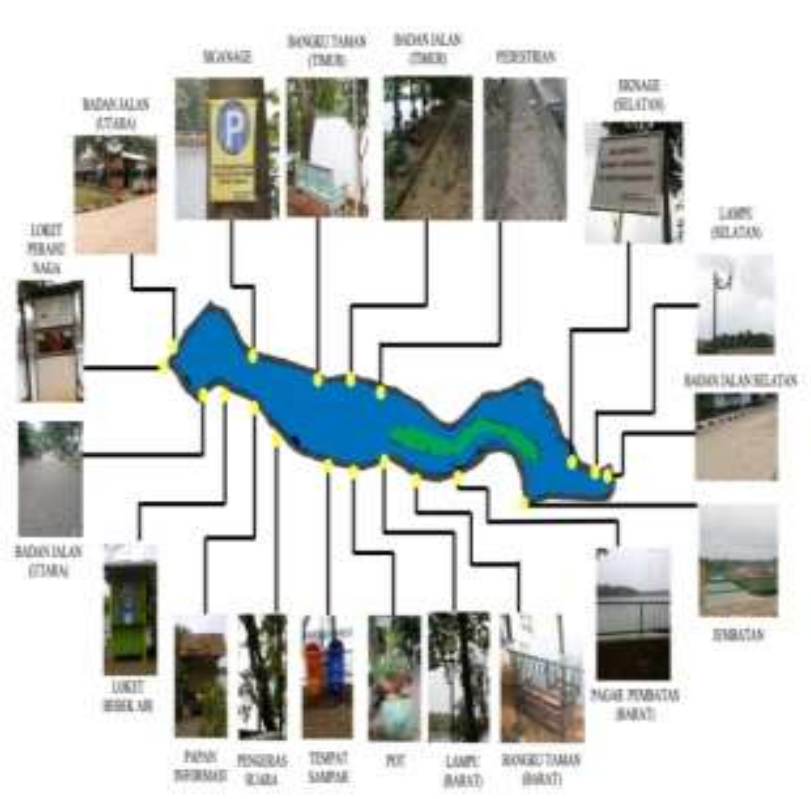

Gambar 6 Titik Elemen Hardscape pada Tapak

(Sumber, Hasil Analisis 2016)

Berdasarkan pengamatan, titik spot hardscape loket perahu naga berada pada bagian utara. Signage terdapat di dua titik bagian barat dan timur. Bangku taman terdapat di dua titik bagian barat dan timur, pedestrian mengelilingi bagian tapak sebelah barat, timur, dan selatan. Lampu taman mengelilingi area lingkar jalan, tempat sampah, pot tanaman, dan papan informasi hanya terdapat pada satu titik pada bagian sebelah barat tapak.

Vegetasi yang terdapat di Kawasan Setu Babakan terdiri dari tanaman yang berfungsi secara ekologis, dan ekonomis. Pada area lingkar Setu babakan banyak tanaman peneduh dan beberapa tanaman buah. Gambar 7

Tanaman di lingkar jalan di Setu Babakan didominasi oleh tanaman-tanaman peneduh. Gloodogan bulat terdapat di titik bagian utara, Karet kebo pada bagian timur tapak.

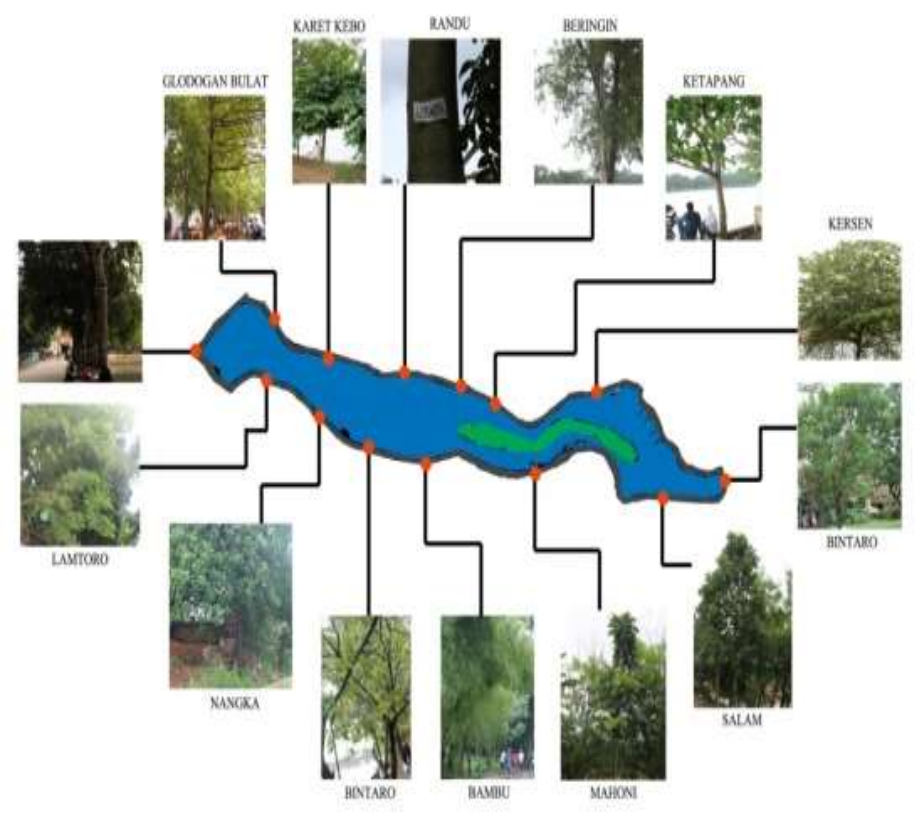

Gambar 7. Vegetasi di Area Lingkar Setu Babakan (Sumber: Hasil Analisis 2015)

Pohon bintaro terdapat di beberapa titik pada bagian barat dan timur. Ketapang terdapat pada titik bagian timur, Kersen berada pada beberapa titik di bagian timur dan selatan tapak.

Aktivitas sosial yang dilakukan di sekitar kawasan lingkar Setu Babakan antara lain duduk-duduk (bersantai), olahraga, menikmati pemandangan Setu babakan, bermain, berjualan makanan (area kuliner), dan berperahu. Gambar 8.

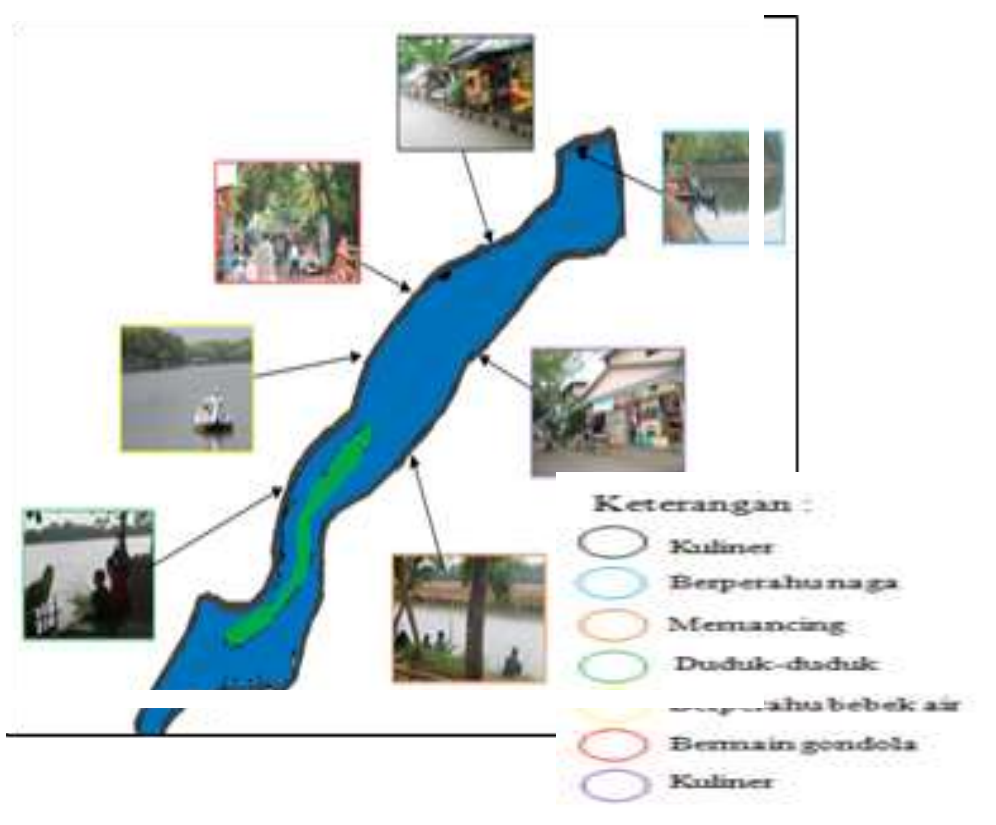

Gambar 8. Aktivitas Pengunjung dan Masyarakat (Sumber: Hasil obeservasi 2015) 
Ornamen sebagai ragam Hias merupakan ragam hias kebudayaan betawi. Umumnya warna khas betawi dibagi menjadi dua. Warna betawi modern dan warna betawi pinggiran. Warna betawi modern lebih cenderung mengadopsi warna-warna natural, seperti coklat muda, coklat tua, dan krem. Sedangkan warna betawi pinggiran terdiri dari warna kuning dan hijau. Ornamen warna betawi juga dipengaruhi oleh kebudayaan dan kulturasi seperti pengaruh adat tionghoa yang lebih didominasi oleh warna merah dan emas. Gambar 9.
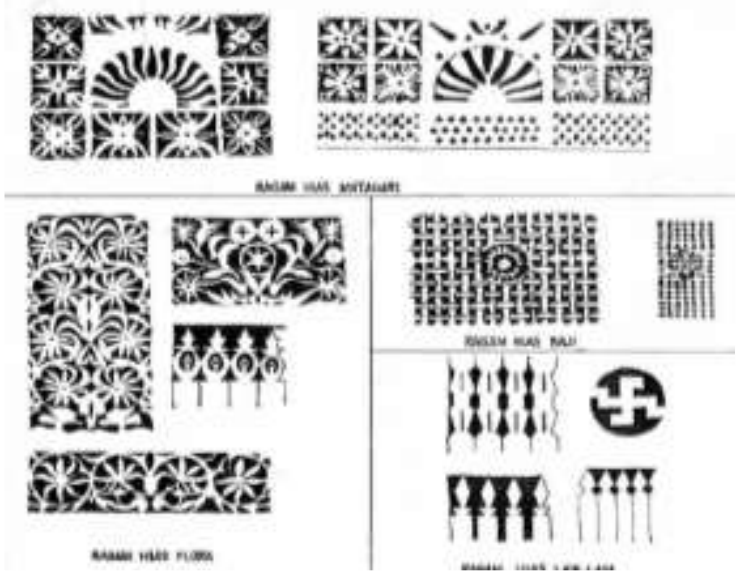

Gambar 9. Jenis Ragam Hias

(Sumber : Harun et al, 1999)

Akses digunakan oleh para pengunjung menggunakan pintu masuk utama, melalui pintu masuk Bang Pitung dan pintu masuk kedua Kawasan PBB bisa dicapai dengan melalui dua jalan utama. Jalan protokol Jl. Raya Pasar Minggu arah selatan kemudian bisa memasuki jalan (Jl.Moch.Kahfi II) dan melalui arah Lenteng Agung (JI.Srengsengsawah). Akses melalui Jl. Srengsengsawah lebih mudah dicapai oleh pengunjung apabila ingin langsung memasuki area lingkar jalan Setu Babakan.

Berdasarkan hasil responden pengguna terdapat beberapa hasil yang diperoleh dari responden, antara lain : Gambar 10.

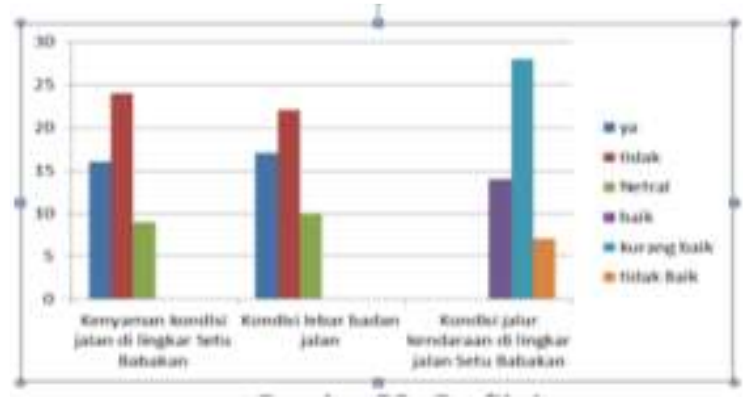

Gambar 10. Kenyaman dan keamanan (Sumber: Analisis 2015)
Sebanyak 16 responden menyatakan nyaman dengan kondisi badan jalan di lingkar Setu Babakan, 24 responden menyatakan tidak nyaman, dan 9 responden menyatakan netral. Sebanyak 17 responden menyatakan bahwa badan jalan cukup lebar. 22 responden menyatakan bahwa badan jalan belum cukup lebar. 10 responden menyatakan netral. Sebanyak 14 responden menyatakan kondisi jalur sirkulasi kendaraan saat ini baik, 28 responden menyatakan kurang baik dan 7 responde menyatakan sangat tidak baik.

Sebanyak 4 responden menyatakan bahwa kondisi penataan area komersil sudah cukup baik. 34 responden menyatakan bahwa penataan area komersil kurang baik dan 11 responden menyatakan sangat tidak baik. Sebanyak 6 responden menyatakan area parkir yang berada dilingkar jalan Setu Babakan sudah mencukupi, 36 responden menyatakan belum mencukupi, dan 7 responden menyatakan netral. Gambar 11.

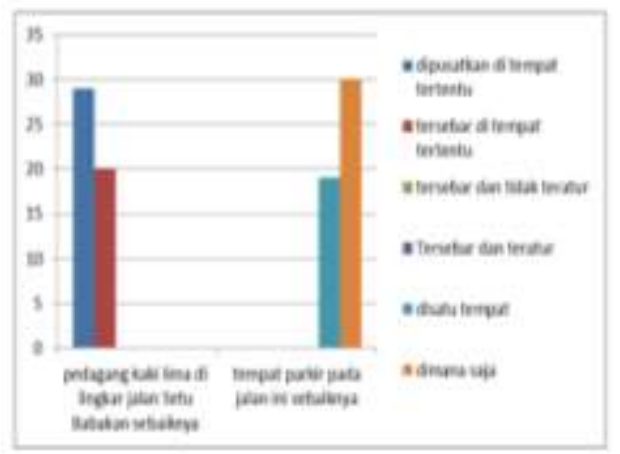

Gambar 11. .Penataan Area Kuliner, parkir (Hasil Analisis, 2015)

Sebanyak 29 responden menyatakan penataan area komersil dipusatkan di tempat tertentu. 20 responden menyatakan tersebar di tempat tertentu. Sebanyak 19 responden menyatakan penataan tempat parkir tersebar dan teratur. 30 responden menyatakan penataan di satu tempat. Gambar 12.

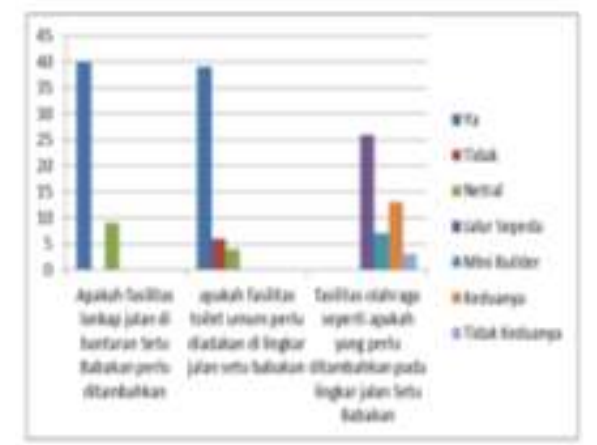

Gambar 12. Fasilitas sarana dan prasarana (Sumber: Hasil Analisis 2015) 
Sebanyak 40 responden menyatakan bahwa fasilitas jalan perlu ditambahkan. 9 responden menyatakan fasilitas tidak perlu ditambahkan. Sebanyak 39 responden menyatakan bahwa fasilitas toilet umum perlu diadakan. 6 responden menyatakan tidak perlu ditambahkan dan 4 responden menyatakan netral. Sebanyak 26 responden menyatakan fasilitas olahraga berupa jalur sepeda perlu diadakan. 7 responden mini builder perlu diadakan, dan 13 responden menyatakan jalur sepeda dan mini builder perlu diadakan. Gambar 13.

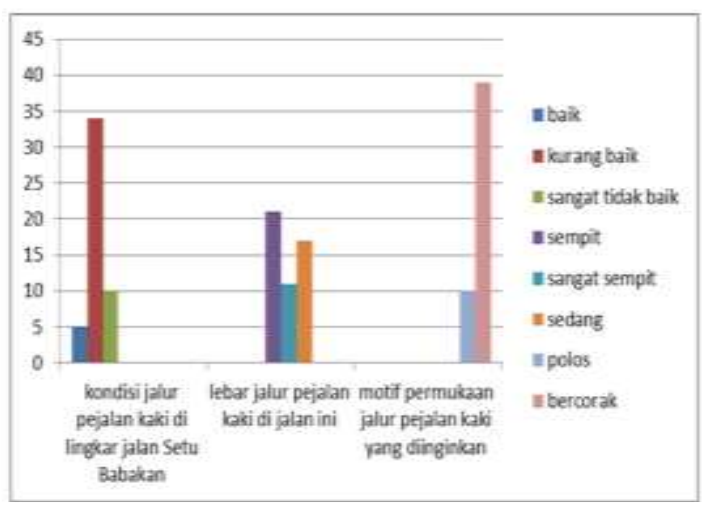

Gambar 13. Jalur Pejalan Kaki

(Sumber : Hasoil Analisis 2015)

Sebanyak 5 responden menyatakan kondisi jalur pejalan kaki dalam kondisi baik, 34 responden menyatakan kurang baik dan 10 responden menyatakan sangat tidak baik. Sebanyak 21 responden menyatakan lebar pejalan kaki sempit. 11 responden menyatakan sangat sempit. 17 responden menyatakan sedang. Sebanyak 10 responden menginkan motif jalur pejalan kaki dengan motif polos dan 39 responden menginginkan motif bercorak.

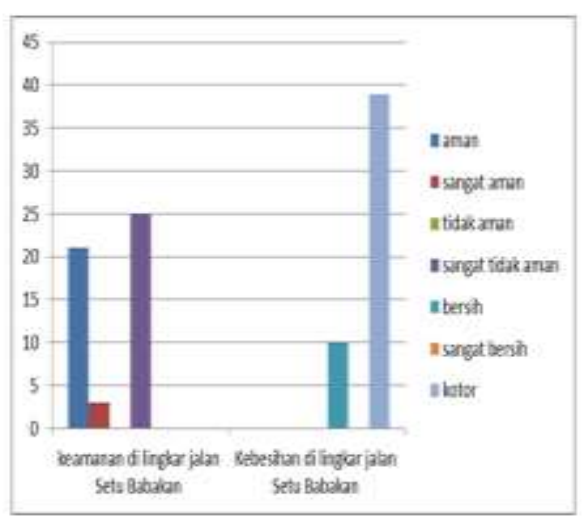

Gambar 14. Kemanan dilingkar Jalan Setu Babakan (Sumber : Hasil Analisis 2015).

Sebanyak 21 responden menyatakan keamanan di lingkar jalan Setu Babakan aman. 3 responden menyatakan sangat aman. 25 responden menyatakan tidak aman. Sebanyak
10 responden menyatakan kebersihan di lingkar Setu Babakan bersih dan menyatakan 39 responden kotor. Kemudian Sebanyak 11 responden menginginkan bentuk tempat sampah tunggal tertutup. 35 responden menginginkan bentuk tempat sampah ganda tertutup dan 3 responden) menginginkan tempat sampah tunggal terbuka. Sebanyak 29 responden menginginkan model tempat sampah modern. 17 responden menginginkan model tradisonal dan 3 responden menginginkan model klasik.

Konsep perncanaan ini diintepretasikan sesuai dengan adat betawi, adat betawi dalam penerapan softscape dan hardscape memiliki konsep ramah lingkungan baik dari softscape dan hardscape. Sebanyak 26 responden menginginkan bentuk lampu penerangan lampu tunggal. 23 responden menginginkan bentuk lampu ganda. Sebanyak 16 responden menginginkan model lampu penerangan modern. 10 responden menginginkan lampu penerangan tradisional dan 22 responden menginginkan lampu klasik. Sebanyak 35 menginginkan bentuk bangku memanjang dan 14 responden menginginkan bentuk bangku melingkar. Sebanyak 20 responden menginginkan mondel bangku modern, 24 responden menginginkan model tradisional dan 5 responden menginginkan bentuk klasik

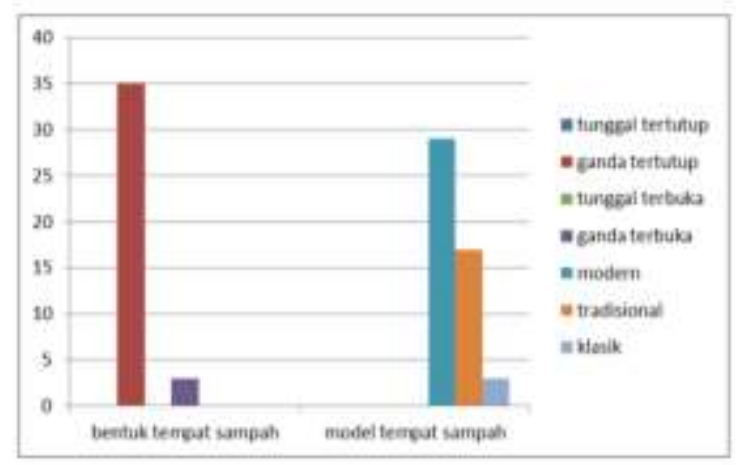

Gambar 15. Konsep Bentuk Elemen Lanskap (Sumber: Hasil Rancangan Konsep Tempat Sampah 2015)

Sebanyak 26 responden menginginkan bentuk lampu penerangan lampu tunggal. 23 responden menginginkan bentuk lampu ganda. Sebanyak 16 responden menginginkan model lampu penerangan modern. 10 responden menginginkan lampu penerangan tradisional dan 22 responden menginginkan lampu klasik. Sebanyak 35 menginginkan bentuk bangku memanjang dan 14 responden menginginkan bentuk bangku melingkar. Sebanyak 20 responden menginginkan mondel bangku modern, 24 responden menginginkan model 
tradisional dan 5 responden menginginkan model klasik.

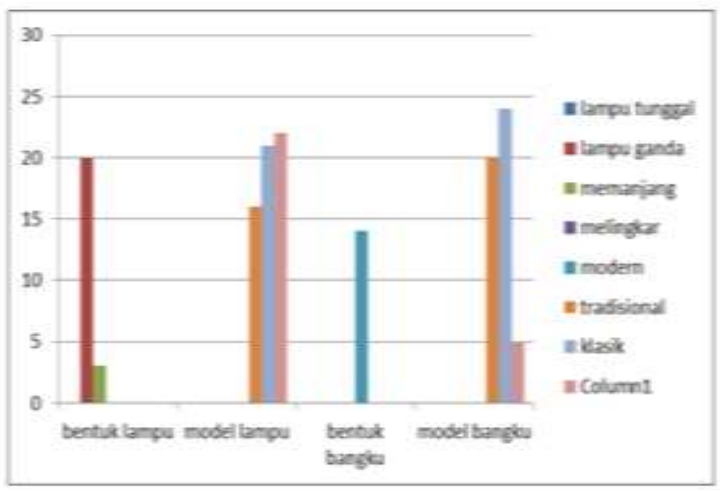

Gambar 16. Konsep bentuk Elemen pendukung . (Sumber : Hasil Konsep Bentuk 2015)

\section{Konsep Perencanaan}

Konsep Perencanaan diarahkan pada pendekatan tema "Street Ecologica of Betawi" pendekatan tema ini bertujuan untuk mengintrepetasikan lanskap jalan di lingkar Setu Babakan menjadi salah satu tujuan wisata di Jakarta Selatan yang dapat menyeimbangkan ekologis pada tapak, memberikan opportunity bagi kondisi lingkungan sekitar dan juga para pengguna sehingga akan menghasilkan suatu lanskap jalan yang memiliki nilai identitas, keindahan, kenyamanan dan keseimbangan bagi lingkungan sekitarnya.

\section{Konsep Bentuk}

Konsep bentuk pada tapak mengintrepetasikan dari bentuk setengah matahari dengan perpaduan kotak wajik. Bentuk tersebut berfilosofi pada kebudayaan Betawi, setengah matahari melambangkan kehidupan menyongsong kedepan dengan penuh semangat, kotak wajik berfilosofi pada terhindar dari bencana. Perpaduan pola ini juga secara tidak langsung berbentuk meander/organis dan geometris (tegak lurus). Dengan konsep bentuk tersebut, perencanaan lanskap jalan di Setu Babakan semakin memiliki nilai identitas bagi suatu kawasan wisata. Gambar 17.

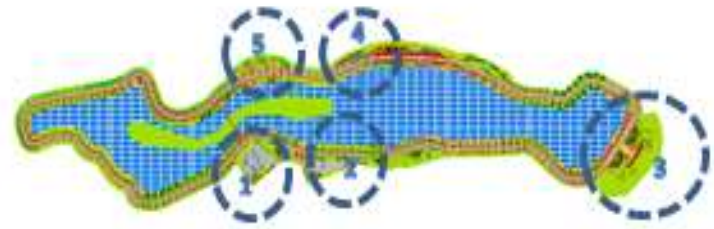

Gambar 17. Konsep BentuK (Sumber: Hasil Rancangan 2015)

Site plan Perencanaan Lanskap Jalan di Kawasan Setu Babakan Studi Kasus : Lingkar Jalan Setu Babakan, terdiri dari rencana ruang jalur hijau jalan, jalur pedestrian, dan fasilitas penunjang wisata dalam hal ini zona-zona kios kuliner. Konsep bentuk pada ruang menggunakan bentuk setengah matahari. Vegetasi yang digunakan terdiri dari beberapa tanaman khas Betawi.

Jalur jalan terdiri dari jalur pedestrian, jalur sepeda, dan delman. Pada pedestrian terdapat beberapa motif paving yang digunakan sebagai simbol kawasan PBB dan estetik. Motif yang digunakan antara lain kotak wajik, bunga cempaka, dan ondel-ondel.

Terdapat titik shelter sepeda, dan drop out delman. Fasilitas kuliner utama terdapat di tiga bagian, sebelah utara dan barat. Kios ini berukuran $3 \times 2 \mathrm{~m}$ dengan jarak antar kios 3 meter, di setiap kios terdapat fasilitas gerobak. Main entrance utama pada lingkar jalan Setu Babakan berada di Jl. Srengsengsawah dan side entrance berada di Jl. Moch. Kahfi II.

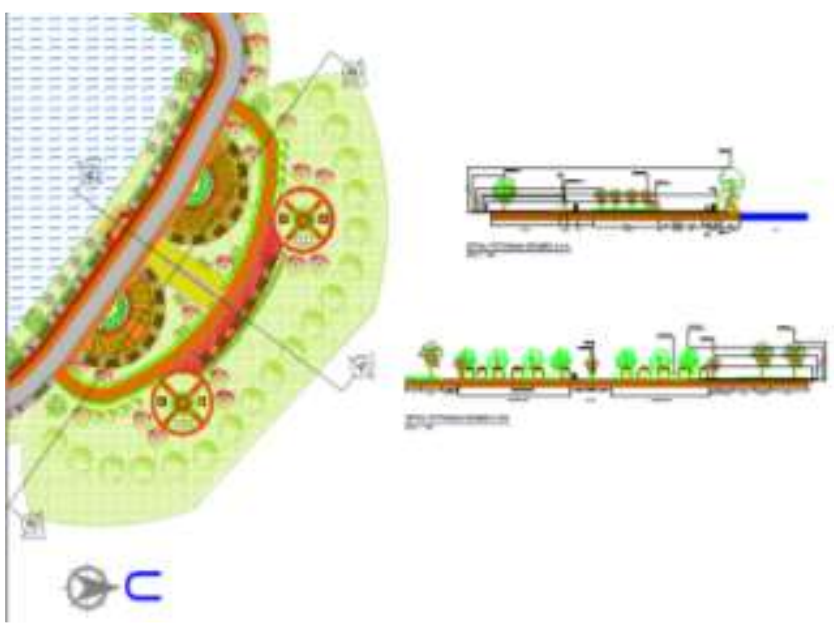

Gambar 18. Site Plan

(Sumber : Hasil Rancangan Tim 2015) 

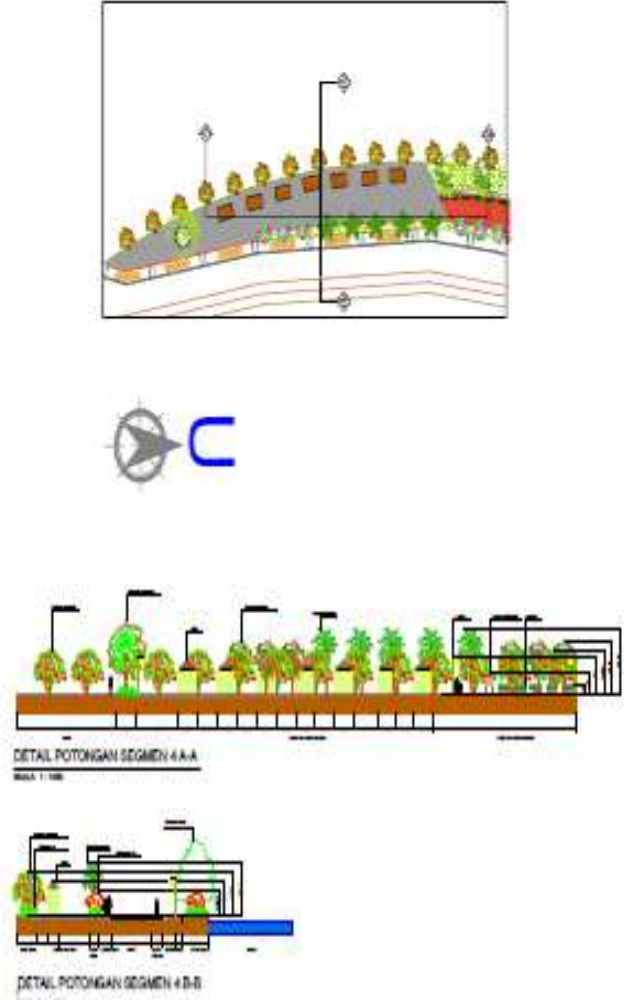

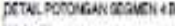

Gambar 19. Detail Potongan

(Sumber : Hasil Rancangan Tim 2015)

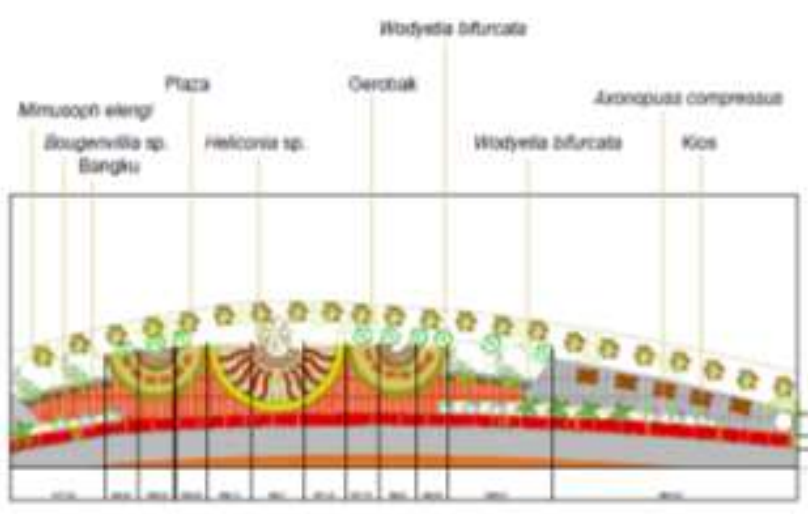

Gambar 20. Site Plan

(Sumber : Hasil Rancangan Tim 2015)

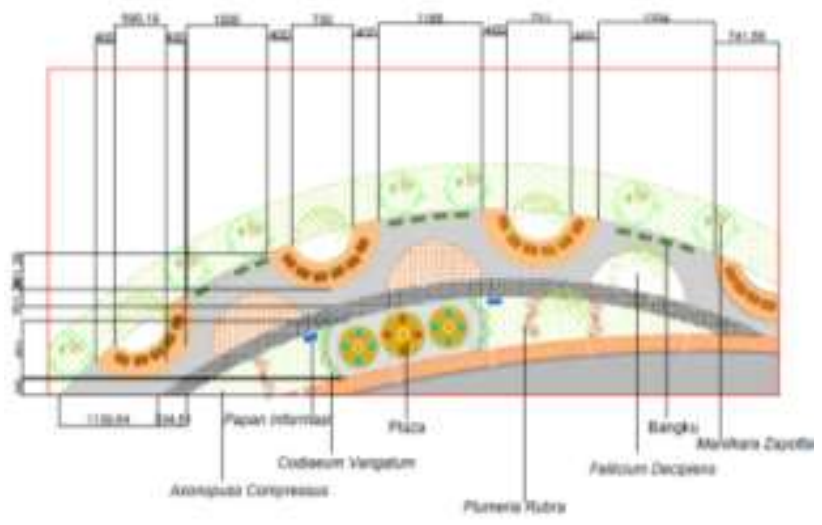

Gambar 21 Detail Potongan

(Sumber : Hasil Rancangan Tim 2015)

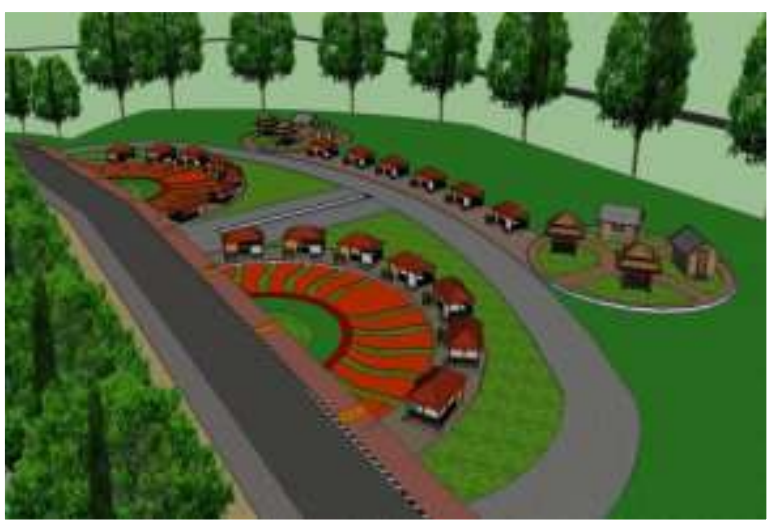

Gambar 22 Detail Potongan

(Sumber : Hasil Rancangan Tim 2015)

\section{KESIMPULAN}

Perkampungan Setu Babakan merupakan salah satu ikon wisata di Jakarta selatan sebagai sarana sarana wisata budaya, konservasi dan rekreasi. Salah satunya lingkar jalan di kawasan wisata Setu Babakan, jalan ini mengelilingi Setu Babakan yang berbatasan dengan permukiman yang mengakibatkan tidak tertatanya area kuliner yang berada di sepanjang lingkar jalan Setu Babakan. Oleh karena itu diperlukannya perencanaan lanskap jalan agar tercipta suatu lanskap jalan agar tercipta kawasan yang konservatif, nyaman, indah tertata mengahasilkan suatu identitas dan bermanfaat bagi pengguna.

Konsep dasar lanskap jalan di kawasan wisata Setu Babakan adalah untuk menciptakan sebuah lankap jalan di kawasan wisata yang memberikan opportunity bagi kondisi lingkungan sekitar dan juga para pengguna sehingga akan menghasilkan suatu lanskap jalan yang memiliki nilai identitas, keindahan, 
kenyamanan dan keseimbangan bagi lingkungan sekitarnya. Konsep perencanaan ini diintepretasikan sesuai dengan adat betawi, adat betawi dalam penerapan softscape dan hardscape memiliki konsep ramah lingkungan baik dari softscape dan hardscape. Identitas ini dapat diwakilkan dengan street furniture/perabot jalan di sepanjang jalan lingkar Setu Babakan maupun vegetasi lokal yang direncanakan.

Selain sebagai identitas perencanaan lanskap jalan di kawasan wisata Setu Babakan juga sebagai penyeimbang dan menciptakan nilai ekologis yang baik bagi lingkungan Setu dan sekitarnya. Perencanaan lanskap jalan ini meliputi tata hijau, fasilitas dalam hal ini kioskios kuliner dan sirkulasi dalam tapak.

Ruang yang direncanakan pada tapak terdiri dari ruang sirkulasi, ruang penyangga/ konservasi, ruang pelayanan, dan ruang identitas. Dalam perencanaan sikulasi direncanakan pelebaran jalur pedestrian untuk memberikan kenyamanan bagi pengguna serta adanya jalur disable. Untuk jalur pejalan kaki direncanakan terdapat beberapa motif aksentual betawi. Selain Jalur pejalan kaki, jalur sepeda dan delman yang menjadi pilihan bagi pengguna dalam mengakses tapak.

\section{DAFTAR PUSTAKA}

[1] Simonds, JO. (1983). Landscape Architecture. New York : McGraw Hill-Book Co.

[2] Ecbo, G. (1964). Urban Landscape Design. New York : McGraw-Hill Book Inc

[3] Carpenter, P.L.T.D. Walker dan F.O. Lanphear. (1975). Plant in the Landscape. New York : W. H. Freeman and Company

[4] Lynch, K. (1981). The Image of the City. Cambridge Mass. M.I.T.prees.

[5] Nurisjah. (2004). Penuntun Praktikum Perencanaan Lanskap. Program Studi Arsitektur Lanskap. Departemen Budidaya Pertanian. Fakultas Pertanian. IPB. Bogor

[6] Harris, C.W dan N.T Dines. (1988) . TimeSaver Standards for Landscape Architecture. New York : McGraw-Hill Book Co.

[7] Arikunto Suharsimi. (2006). Metodologi Penelitian. Yogyakarta. Bina Aksara

[8] Sugiarto, dkk. (2003). Teknik Sampling. Jakarta: Gramedia

[9] Status Lingkungan Hidup Daerah Provinsi DKI Jakarta. (2011). Pemerintah Provinsi DKI Jakarta. 
